Saudi Journal of Medical and Pharmaceutical Sciences

Abbreviated Key Title: Saudi J Med Pharm Sci

ISSN 2413-4929 (Print) |ISSN 2413-4910 (Online)

Scholars Middle East Publishers, Dubai, United Arab Emirates

Journal homepage: https://saudijournals.com/sjmps

Original Research Article

\title{
Formulation Optimization, Permeation Kinetic and Release Mechanism Study of In-Situ Nasal Gel Containing Ondansetron
}

Pintu Kumar De ${ }^{1 *}$, Souvik Ghatak ${ }^{2}$

${ }^{1}$ Associate Professor, Department of Pharmaceutical Technology, JIS University, 81, Nilgunj Road, Agarpara, Kolkata-700109, West Bengal, India

${ }^{2}$ Department of Pharmaceutical Technology, JIS University, 81, Nilgunj Road, Agarpara, Kolkata-700109, West Bengal, India

DOI: $10.36348 /$ sjmps.2020.v06i01.014 $\quad$ | Received: 11.01 .2020 | Accepted: 18.01 .2020 | Published: 27.01 .2020

*Corresponding author: Dr. Pintu Kumar De

Abstract

Systemic delivery of drugs through nasal route requires extended residence time in nasal cavity. The aim of the present work is to fabricate an In-Situ nasal gel using thermoreversible polymer, PF-127 and mucoadhesive polymers HPMC E15 and PEG 6000 to improve the residence time and easy application of accurate dosage. Optimization of formulations was carried out in terms of their content uniformity, clarity, $\mathrm{pH}$, gelation temperature, viscosity, mucoadhesive strength and spreadability. Drug-excipient compatibility was ascertained by FT-IR Spectroscopy. Optimization of PF-127 concentration (20 and $25 \%$ ) was done to get gelation temperature of formulations in the nasal physiological temperature range $\left(25-34^{\circ} \mathrm{C}\right)$. The regression value of ex vivo permeation kinetic study show highest linearity for F1 and $\mathrm{F} 2$ to the Higuchi Model whereas F3, F4, F5, F6 to the first order model \& the 'n' value of each formulation shown that F1, F2 follow Non- Fickian release and F3, F4, F5, F6 follow Super Case II release mechanism. The value of exponent 'n' of Korsmeyer-Peppas model suggests the permeation from F1 \& F2 is diffusion \& erosion controlled, and F3, F4, F5 \& F6 is due to the erosion of the polymeric chain. It can be concluded that as viscosity of the formulation is increased the release mechanism will transform from Non - Fickian to Super Case II release mechanism. Hence a clear In-Situ gel may be formulated using PF 127 which is a stable under accelerated conditions and releases the drug under controlled manner for sustained systemic delivery through nasal route.

Keywords: In-Situ Gel, Nasal gel, Thermo-sensitive polymer, PF-127, Release mechanism.

Copyright @ 2020: This is an open-access article distributed under the terms of the Creative Commons Attribution license which permits unrestricted use, distribution, and reproduction in any medium for non-commercial use (NonCommercial, or CC-BY-NC) provided the original author and source are credited.

\section{INTRODUCTION}

The intranasal administration is an effective way to deliver the drug for systemic action as an alternative to oral and intravascular routes, although the oral route remains the most popular for systemic drug administration, low oral bioavailability of some compounds has prompted the search of more effective routes for their systemic delivery [1]. Intranasal delivery seems to present fast and extended drug absorption [2], which has been supported by many studies for comparison of intranasal drug delivery against oral and parenteral administration. Some of the prominent studies include analgesics (morphine) [3], cardiovascular drugs as propranolol and carvedilol [4], hormones such as levonorgestrel, anti-inflammatory agents as indomethacin and ketorolac, and antiviral drugs (acyclovir).

In general, among the primary targets for intranasal administration are pharmacologically active compounds with poor stability in gastrointestinal fluids, poor intestinal absorption and/or extensive hepatic firstpass elimination, such as peptides, proteins and polar drugs [3]. Potential for direct delivery of drug to the central nervous system via the olfactory region, thus bypassing the blood brain barrier [5]. Direct delivery of vaccine to lymphatic tissue and induction of a secretory immune response at distant mucosal site [6]. Low residence time of drug in nasal cavity is due to the rapid mucocilliary clearance (MCC) affect absorption and ultimately the bioavailability of drug. Hence mucoadhesive polymers are used in the formulations to prolong the residence time at the nasal absorption site and thereby facilitate the uptake of the drug. It is difficult to administer an accurate dosage with the ordinary gels, whereas In-Situ gels are easy to apply in liquid form accurately with the help of a dropper and are instantly converted into gel upon instillation into the nasal cavity. Hence the objective of the present study is designed was to fabricate an In-Situ nasal gel using thermoreversible polymer, PF-127 and mucoadhesive polymers HPMC E15 and PEG 6000 to improve the 
Pintu Kumar De \& Souvik Ghatak; Saudi J Med Pharm Sci, Jan., 2020; 6(1): 91-101

residence time and easy application of accurate dosage of the applied drug, ondansetron hydrochloride and to study the release mechanisms from different formulations.

\section{Materials AND Methods MATERIALS}

Ondansetron Hydrochloride (ONH) and PF 127 were donated by Albert David Ltd, Kolkata, India. HPMC E15 LV Premium was purchased from Loba Chemie Pvt Ltd, India. PEG6000, Potassium Chloride and Calcium Chloride were procured from Merck Specialities Private Limited. LA 393 Dialysis Membrane - 70 was purchased from HiMedia Laboratories Ltd.

\section{Preparation of simulated nasal electrolyte solution} Simulated Nasal Fluid (SNF) is prepared by using the formula as described by Y. Cheng et al., [7] dissolving $8.77 \mathrm{~g}$ of sodium chloride, $2.98 \mathrm{~g}$ of potassium chloride and $0.59 \mathrm{~g}$ of calcium chloride in 1 liter of distilled water $\&$ the $\mathrm{pH}$ was adjusted to 5.5.

\section{Determination of partition co efficient}

$25 \mathrm{ml}$ of SNF \& $25 \mathrm{ml}$ of $\mathrm{n}$-octanolwere taken in a $100 \mathrm{ml}$ conical flask. Then $2 \mathrm{mg} \mathrm{ONH}$ was added in the conical flask. Then shaken it for $6 \mathrm{~h}$ with mechanical shaker. Both oil and buffer phase was separated and then measured the absorbance in UVspectrophotometer at $249 \mathrm{~nm}$. Value of partition co efficient $(\mathrm{P})$ was determined with the help of following equation:-

$$
\mathrm{P}=\frac{\text { concentration of drug in octanol }}{\text { concentration of drug in buffer }}
$$

\section{Determination of permeability coefficient}

It was done by taking the Goat Nasal Membrane with the saturated solution of the drug in the simulated nasal fluid. Permeability Coefficient was calculated at steady-state condition by using the following formula [8].
Where

$$
\text { Permeability coefficient }=\frac{\mathrm{Jss}}{\mathrm{CV}}
$$

Jss $=$ slope of linear portion of graph of amount of drug permeated per unit area Vs time,

$\mathrm{Cv}=$ Initial donor concentration.

\section{Drug polymer compatibility study by FTIR}

To study the possible interaction between the drug $(\mathrm{ONH})$ with other components of formulations like PF-127, PEG 6000 and HPMC E15, FTIR was carried out on physical mixtures of pure substances and formulation. The IR spectra were recorded using IR Spectrophotometer (Alpha - A4 size FT-IR, BRUKER, Germany).

\section{Optimization of plain and drug loaded PF-127 gels}

The plain and drug loaded PF-127 gels were prepared by cold method described by Schmolka et al., [9]. For drug loaded PF-127 gels, $1 \%$ of ONH was stirred with sufficient quantity of double distilled water while for plain PF-127 gels, only sufficient quantity of double distilled water without $\mathrm{ONH}$ was kept overnight at $4^{0} \mathrm{C}$ in refrigerator. The PF-127 was added slowly with continuous stirring. The dispersions were then stored in a refrigerator until clear solution was obtained and finally volume was adjusted. Optimization of plain and drug loaded PF-127 gels were done by varying concentration of PF-127 and evaluating them for gelation temperature.

\section{Preparation of mucoadhesive thermoreversible nasal gels}

ONH along with mucoadhesive polymer HPMC E15, and PEG 6000 and Methyl paraben were dissolved in double distilled water by agitation at room temperature. After cooling the solution to $4^{0} \mathrm{C}, \mathrm{PF}-127$ was added slowly with agitation. The resulting dispersion was then kept overnight at $4{ }^{0} \mathrm{C}$ until clear and viscous transparent solution was formed. Finally volume was adjusted by using cold distilled water. The composition of 6 different formulations is given in Table-1.

Table-1: Composition of mucoadhesive thermoreversible nasal gels

\begin{tabular}{|l|l|l|l|l|l|l|}
\hline Code & Drug (\%) & PF-127 (\%) & PEG 6000 (\%) & Methyl paraben (\%) & HPMC E 15 (\%) & Water \\
\hline F1 & 1 & 20 & 1.5 & 0.2 & 1 & 5 \\
\hline F2 & 1 & 20 & 1 & 0.2 & 1 & 5 \\
\hline F3 & 1 & 20 & 0.5 & 0.2 & 1 & 5 \\
\hline F4 & 1 & 25 & 1.5 & 0.2 & 1 & 1 \\
\hline F5 & 1 & 25 & 1 & 0.2 & 1 & 5 \\
\hline F6 & 1 & 25 & 0.5 & 0.2 & 5 \\
\hline
\end{tabular}

\section{Drug Content Uniformity}

$5 \%$ Solution of each preparation is made with simulated nasal fluid and make proper dilution to make the concentration to $10 \mu \mathrm{g} / \mathrm{ml}$ and measure the absorbance in spectrophotometer (Shimazhu UV-Vis, Model -1700) at 249nm.
Clarity

The clarity of various formulations was determined by visual inspection under black and white background and it was graded as follows; turbid: +, clear: ++ , very clear (glassy): +++ . 
pH

$5 \%$ solution is made of each formulation using distilled water \& $\mathrm{pH}$ of resulting solution was determined by using $\mathrm{pH}$ meter

\section{Gelation Temperature}

The gelation temperature of aqueous solution of PF-127 was measured by using procedures reported by Choi et al., [10]. $10 \mathrm{ml}$ volume of solution was transferred to $20 \mathrm{ml}$ transparent vial containing a magnetic bar. The vial was heated at an increasing rate of $1^{\circ} \mathrm{C} / \mathrm{min}$ with constant stirring at $100 \mathrm{rpm}$. The temperature at which rotation of bar stopped was taken as the gelation temperature.

\section{Viscosity}

The viscosities of various formulations were measured with increase in temperature by using Cone and Plate viscometer (Brookfield viscometer Model Cap $2000+2$ ).

\section{Mucoadhesive Strength}

The mucoadhesive strength was determined by using the method reported by Choi et al., [11].

\section{Spreadability}

The spreadability in terms of flow ability of various mucoadhesive thermo-reversible gels was determined [12]. For assessing spreadability a rectangular, hollow, glass chamber $(10 \times 6 \times 4 \mathrm{~cm})$ was used. Provision was made to the chamber for inlet and outlet of hot water. The sheep nasal mucosa from serosal side was pasted on chamber. Then hot water was circulated for 15-20 min for acquiring temperature of mucosa to $34 \pm 2{ }^{\circ} \mathrm{C}$. One drop of formulation was placed on mucosa at an angle of $120^{\circ}$ and the distance traveled by drop before it gets converted into gel was determined. Measurements were repeated six times for each of the gel preparation.

\section{In-Vitro Permeation Studies}

In - vitro permeation studies are performed by using the dialysis bag [13] with the diameter of 17.5 $\mathrm{mm} \&$ flat width of $29.31 \mathrm{~mm}$ and molecular weight cut off 1200-1400 KDa (Himedia-70) with a carrying capacity of $2.41 \mathrm{ml} / \mathrm{cm}$. First we take the dialysis tube which is $1 \mathrm{~cm}$ in length. Then take $1 \mathrm{ml}$ formulation into the tube. After that the tube are suspended in the dialysis beaker containing $80 \mathrm{ml}$ of SNF which adjusted to a temperature of $37^{\circ} \mathrm{C}$. At predetermined time intervals, $1 \mathrm{ml}$ of sample was withdrawn from the acceptor compartment and replaced the sample volume with SNF pH 5.5 after each sampling. The samples withdrawn were diluted to $10 \mathrm{ml}$ by $\mathrm{SNF}$, filtered and used for analysis. The amount of permeated drug was determined using UV-visible spectrophotometer $(\lambda$ $\max =249 \mathrm{~nm})$. In vitro drug permeation was carried out in triplicate.

\section{Ex-Vivo Permeation Studies}

Fresh nasal mucosa was carefully removed from the nasal cavity of goat obtained from the local slaughterhouse. The mucosa was stored in normal saline with few drops of gentamycin sulphate injection to avoid bacterial growth. After the removal of blood and bony cartilage from the mucosal membrane it becomes ready to use [14]. Franz Diffusion Cell was used to study in vitro drug permeation profile. $67 \mathrm{ml}$ of simulated nasal electrolyte solution, SNF pH 5.5 at $34^{\circ} \mathrm{C}$ was added to the acceptor chamber. The temperature within the chamber was maintained at $34^{\circ} \mathrm{C}$ by circulating hot water. After a pre incubation time of $20 \mathrm{~min}$, formulation equivalent to $2 \mathrm{mg}$ of $\mathrm{ONH}$ was placed in donor chamber. At predetermined time intervals, $1 \mathrm{ml}$ of sample was withdrawn from the acceptor compartment and replaced the sample volume with SNF pH 5.5 after each sampling. The samples withdrawn were diluted to $10 \mathrm{ml}$ by SNF, filtered and used for analysis. The amount of permeated drug was determined using UV-visible spectrophotometer $(\lambda$ $\max =249 \mathrm{~nm}$ ). Ex-Vivo drug permeation was carried out in triplicate.

\section{Analysis of drug release data}

The drug release data was fitted to different kinetic models [15] like Zero order Model, First order Model, Higuchi Model and Korsmeyer-Peppas Model. Interpretation of diffusional release mechanism was done as per following Table-2.

Table-2: Interpretation of diffusional release mechanisms from polymeric films

\begin{tabular}{|l|l|}
\hline Release exponent (n) & Drug transport mechanism \\
\hline 0.5 & Fickian diffusion \\
\hline $0.45<\mathrm{n}=0.89$ & Non -Fickian transport \\
\hline 0.89 & Case II transport \\
\hline Higher than 0.89 & Super case II transport \\
\hline
\end{tabular}

\section{Stability Study}

Stability study of all the six formulations were carried out at intermediate \& accelerated conditions in closed containers according to the ICH guideline Q1A specifications given in table 3 . In both cases sapling were done 3 times i.e., $0,3 \& 6$ months \& performed test for the drug content uniformity, gelation temperature, $\mathrm{pH} \&$ clarity to see the effect of temperature \& humidity on product stability. 
Table-3: Different Stability Study Conditions according to the ICH guide line.

\begin{tabular}{|l|l|l|l|}
\hline Study & Storage condition & $\begin{array}{l}\text { Minimum time period covered } \\
\text { by data at submission }\end{array}$ & Sapling interval \\
\hline Intermediate & $30^{\circ} \mathrm{C} \pm 2{ }^{\circ} \mathrm{C} / 65 \% \mathrm{RH} \pm 5 \% \mathrm{RH}$ & 6 months & 0,3 \& 6 months \\
\hline Accelerated & $40^{\circ} \mathrm{C} \pm 2^{\circ} \mathrm{C} / 75 \% \mathrm{RH} \pm 5 \% \mathrm{RH}$ & 6 months & 0,3 \& 6 months \\
\hline
\end{tabular}

\section{RESUlTS AND DiSCUSSION}

\section{Partition Co-efficient}

To assess the partitioning of drug between Nasal Mucosa and in vitro study fluid (SNF, $\mathrm{pH} 5.5$ ), the partition coefficient was determined. The calculated logarithmic value of Partition co-efficient ( $\log p$ ) of $\mathrm{ONH}$ in $\mathrm{n}$-Octanol / SNF of $\mathrm{pH} 5.5$ is 1.20 .

The result indicates that the drug have sufficient lipophilicity, which is necessary to formulate In-Situ Nasal Gel.

\section{Permeability Co-efficient}

For the optimum trans-mucosal permeability the permeability co-efficient should be $\geq 0.5 \times 10^{-}$ ${ }^{3} \mathrm{~cm} / \mathrm{h}$. Experimentally the permeability co-efficient of $\mathrm{ONH}$ was found $3.65 \times 10^{-2} \mathrm{~cm} / \mathrm{h}$ through Goat Nasal Mucosa which is greater than the required value. As a result diffusion of $\mathrm{ONH}$ through Nasal Mucosa is expected to be good enough to formulate it in the InSitu Nasal Mucoadhesive Gel.

\section{FTIR Study}

Drug-excipients interaction is one of the most important characteristics that regulate the availability of drug from the formulation, its release pattern, and it's stability in the formulation [16]. The FTIR-Spectrum of pure drug ONH, PF-127, PEG 6000, HPMC E15 \& the formulation containing $\mathrm{ONH}$ along with PF-127, PEG 6000 \& HPMC E 15 are shown in Fig 1-5 respectively.

The peak maximum of the $\mathrm{ONH}$ due to functional group presents in it [17], is matched with the peak appear on spectrum of the pure drug $(\mathrm{ONH})$ and the Formulation of drug and polymers. The peak maximum of assignments of $\mathrm{ONH} \&$ formulation are given in Table-4.

Table-4: Peak maximum of ondansetron $\mathrm{HCl} 2 \mathrm{H}_{2} \mathrm{O}$ for IR study

\begin{tabular}{|l|l|l|}
\hline Assignment & $\begin{array}{l}\text { Peak maximum }\left(\mathbf{c m}^{-1}\right) \\
\text { Pure ONH }\end{array}$ & $\begin{array}{l}\text { Peak maximum }\left(\mathbf{c m}^{-1}\right) \\
\text { Formulation }\end{array}$ \\
\hline C aromatic & 1531 & 1457.11 \\
\hline C=N,C=O starching & 1623 & 1638.08 \\
\hline Aliphatic CH starching & 2936.43 & 2925.10 \\
\hline C=C aromatic & 1531 & 1542 \\
\hline OH starching & 3408.33 & 3346.89 \\
\hline
\end{tabular}

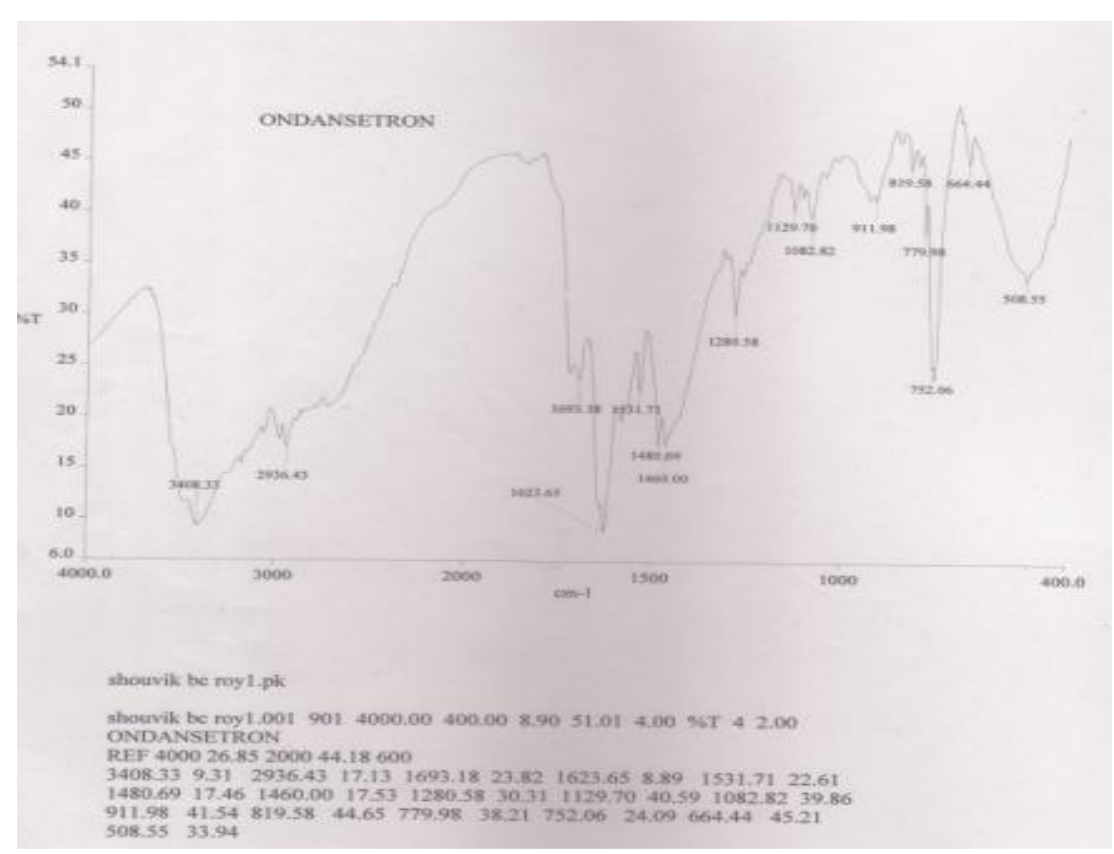

Fig-1: FTIR Spectrum of Ondansetron Hydrochloride 


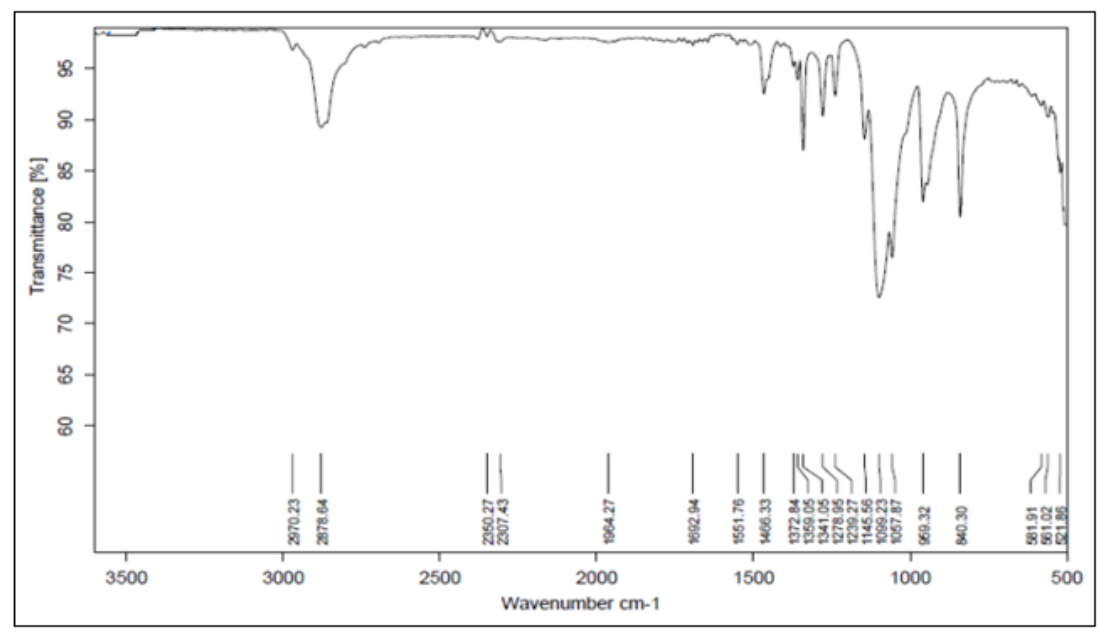

Fig-2: FTIR spectra of PF 127

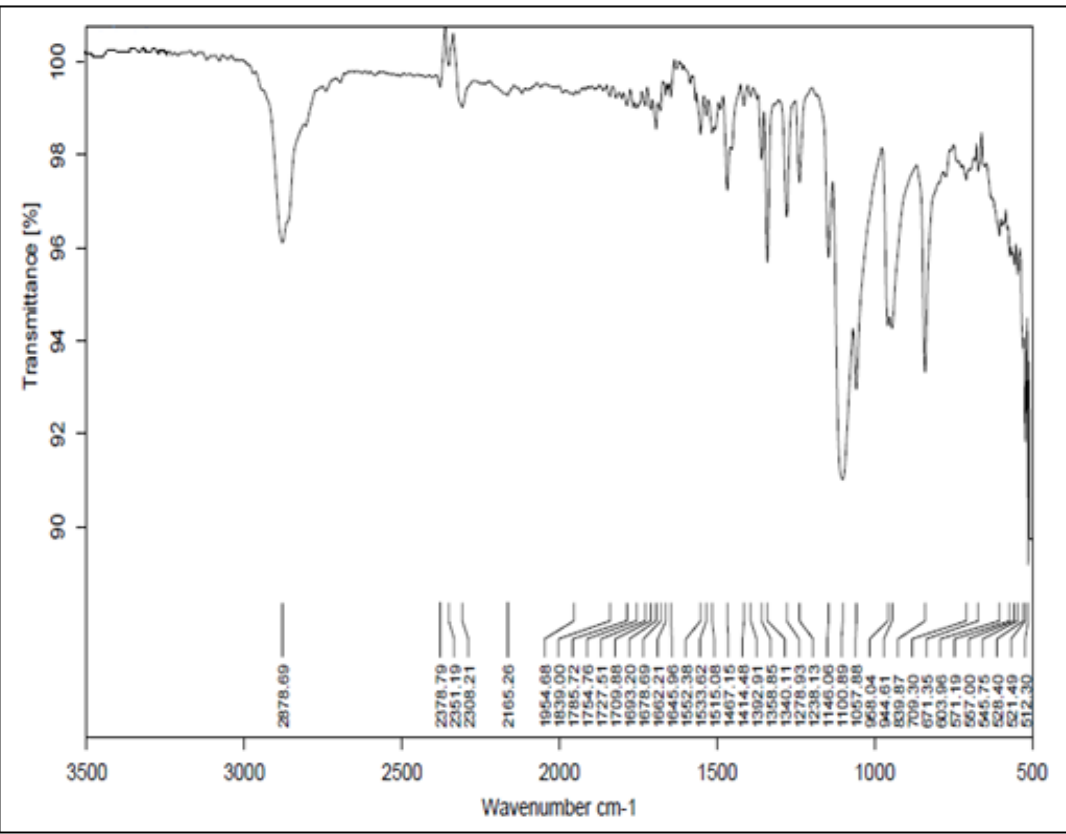

Fig-3: FTIR Spectra of PEG 6000

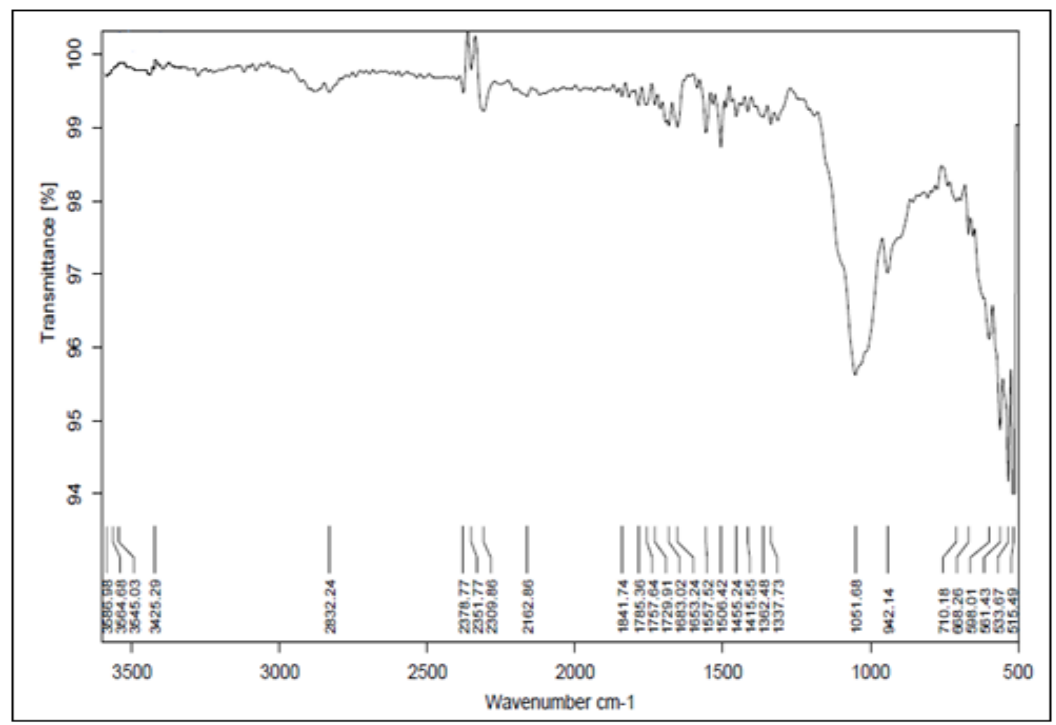

Fig-4: FTIR Spectra of HPMC E15 


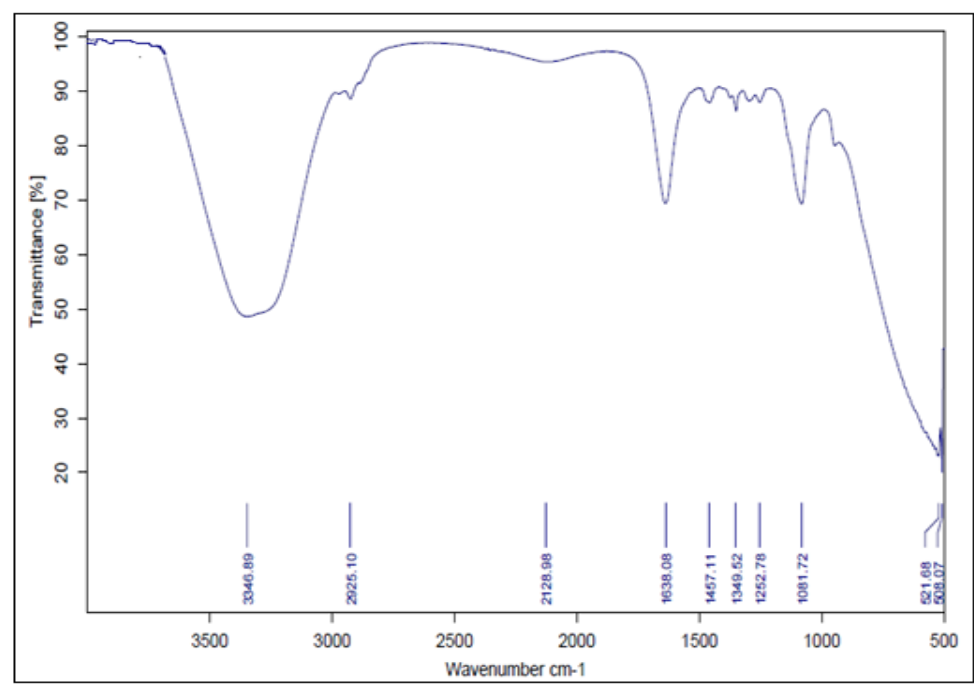

Fig-5: FTIR Spectrum of the gel containing Ondansetron Hydrochloride along with PF-127, PEG 6000 \& HPMC E 15

The presence of all major peaks responsible for functional groups of the pure drug ascertained the absence of drug polymer interaction in the formulation and the components are quite safe with respect to cross reaction, which have often found while producing different formulations.

\section{Optimization of concentration of PF-127}

Gelation temperatures for plain PF-127 gels were observed for the concentration range of $10,15,18$, $20,25,30 \% \mathrm{w} / \mathrm{v}$ of PF-127 and it was found that the gelation temperature of plain PF-127 gels decreased with increasing concentration of PF-127(Fig-6). When $1 \%$ of ONH was added into PF-127 gels, it was found that gelation temperature of each formulation increased significantly. It was found that only $20 \& 25 \%$ of PF-
127 showed ability to form gel with drug in the range of 25 to $32^{\circ} \mathrm{C}$. So, $20,25 \% \mathrm{w} / \mathrm{v}$ concentration of PF 127 was used for further studies.

The decrease in the gelation temperature with increase in PF-127 concentration may be attributed to the higher number and volume occupied by micelles at low temperature. As the concentration of PF-127 increases, the gel structure becomes more closely packed with the arrangement in the lattice pattern.

As $20 \%$ PF $127 \& 25 \%$ PF 127 containing gels show the gelation temperature closer to the nasal temperature, so these two concentrations have been used for the formulation study.

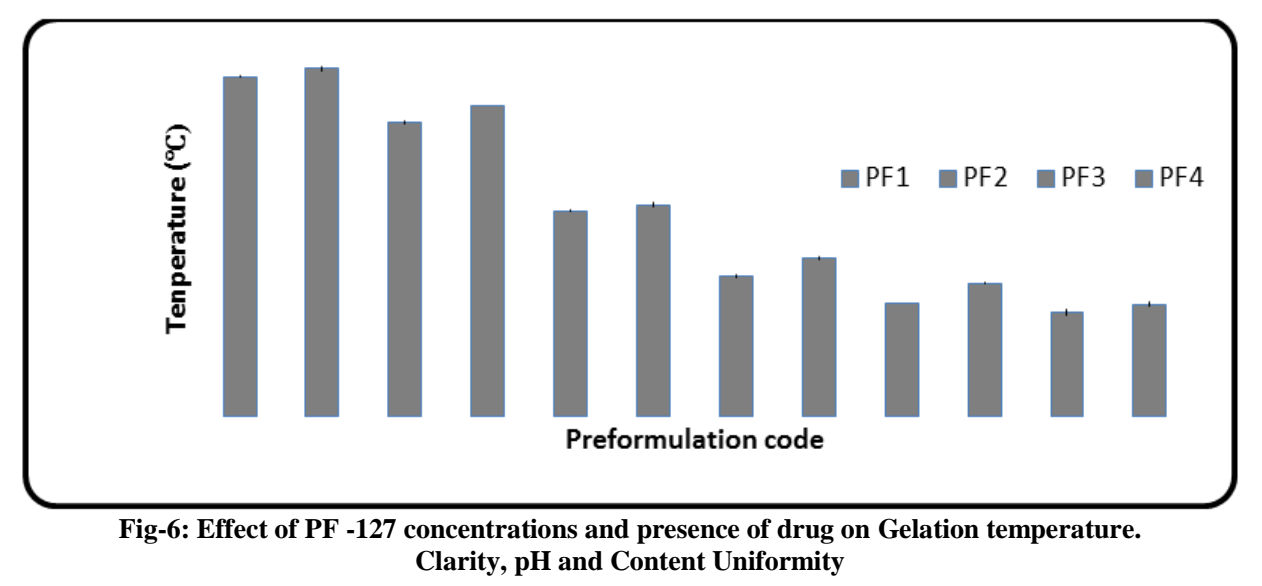

All the prepared sets of formulations were found to be clear. $\mathrm{pH}$ of all the formulations was found in the range of 5.0 to 5.77 (Table-5). The percentage drug content of all prepared nasal formulations were checked and found to be in the range of $97-101 \%$ (Table-5). 


Table-5: Clarity, pH, Content Uniformity of the Six Formulations
\begin{tabular}{|l|l|l|l|}
\hline Formulation code & Clarity & pH & Content uniformity \\
\hline F1 & +++ & $5.77 \pm 0.05$ & $98.5 \% \pm 0.03$ \\
\hline F2 & +++ & $5.47 \pm 0.05$ & $97.6 \% \pm 0.042$ \\
\hline F3 & +++ & $5.4 \pm 0.08$ & $98.4 \% \pm 0.067$ \\
\hline F4 & ++ & $5.1 \pm 0.08$ & $99.1 \% \pm 0.023$ \\
\hline F5 & ++ & $5.2 \pm 0.14$ & $98.2 \% \pm 0.031$ \\
\hline F6 & ++ & $5.0 \pm 0.08$ & $97.3 \% \pm 0.021$ \\
\hline
\end{tabular}

$+++=$ Very Clear; $++=$ Clear. The Values are representedas mean \pm SD $(\mathrm{n}=6)$

From the above Table- 5 it has been observed that formulation F1, F2 \& F3 are very clear and F4, F5 \& F6 are clear. As the $\mathrm{pH}$ of the formulations remain within the range (5-5.7), it does not produce problem to the lysozyme activity. The content uniformity of all the formulations remains between $97-99 \%$.

\section{Gelation Temperature, Mucoadhesive Strength and Spreadability}

The list of the gelation temperature, mucoadhesive strength \& Spreadability data of the 6 formulations is shown in Table-6.

Table-6: Gelation Temperature, Mucoadhesive Force, spreadability of six formulations
\begin{tabular}{|l|l|l|l|}
\hline $\begin{array}{l}\text { Formulation } \\
\text { Code }\end{array}$ & $\begin{array}{l}\text { Gelation } \\
\text { Temperature }\left({ }^{\circ} \mathbf{C}\right)\end{array}$ & $\begin{array}{l}\text { Mucoadhesive } \\
\text { Strength }\left(\mathbf{d y n e} / \mathbf{c m}^{\mathbf{2}}\right)\end{array}$ & $\begin{array}{l}\text { Spreadability } \\
(\mathbf{c m})\end{array}$ \\
\hline F1 & $31.32 \pm 0.14$ & $9905.85 \pm 1.7$ & $3.16 \pm 0.04$ \\
\hline F2 & $32.51 \pm 0.02$ & $10514.38 \pm 2.52$ & $2.72 \pm 0.07$ \\
\hline F3 & $33.79 \pm 0.50$ & $11711.26 \pm 2.86$ & $2.28 \pm 0.04$ \\
\hline F4 & $25.26 \pm 0.25$ & $13546.66 \pm 1.58$ & $1.80 \pm 0.07$ \\
\hline F5 & $26.38 \pm 0.14$ & $13994.89 \pm 1.32$ & $1.10 \pm 0.04$ \\
\hline F6 & $28.29 \pm 0.33$ & $14525.99 \pm 3.69$ & $0.96 \pm 0.05$ \\
\hline
\end{tabular}

Values are shown as mean \pm SD $(n=6)$

The Gelation Temperature is decreased with increase in the concentration of PEG 6000 in both $20 \%$ $\& 25 \%$ PF 127 containing formulations, which is due to the formation of higher number of mixed micelle.

Mucoadhesive strength increases with decreased concentration of PEG 6000 (Table-6). This is because the increased concentration of PEG produces higher percentage of mixed micelle which retarded the formation of hydrogen bonding between mucoadhesive polymer and mucosal membrane.
Assessment of Spreadability in terms of distance traveled by in situ nasal gels reveals that Spreadability may be related to the viscosity of in situ nasal gels. Increase in viscosity of the formulations decreases the distance traveled by in situ nasal gels.

\section{Viscosity studies}

The plots of viscosity versus temperature for various nasal In-Situ gelling formulations are shown in Fig-7. There was no considerable change in viscosity up to the point of gelation temperature. Sharp rise in viscosity was observed at the point of sol-gel transition.

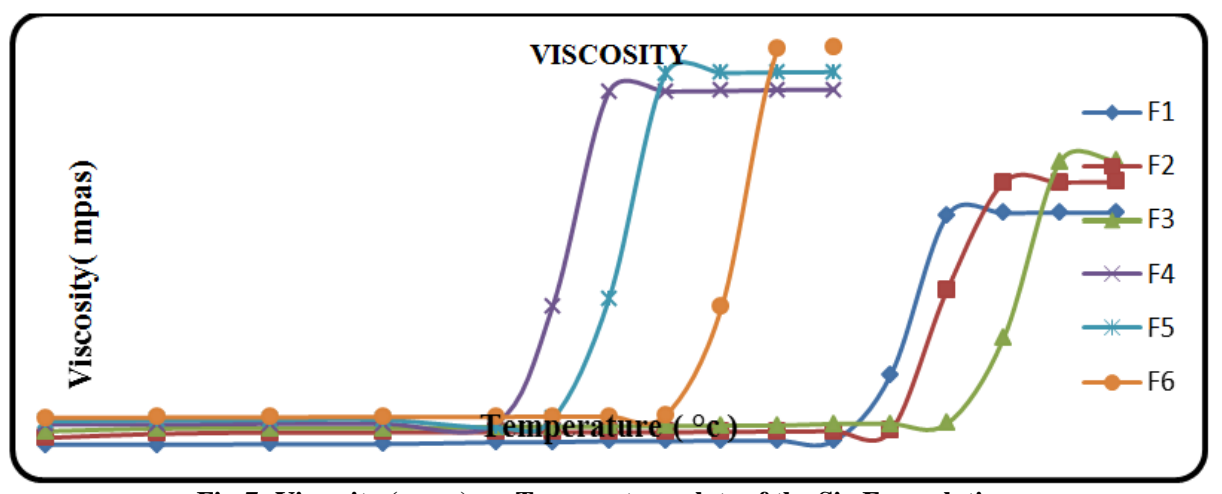

Fig-7: Viscosity (mpas) vs. Temperature plots of the Six Formulations

The viscosity studies of all formulations show that they are in a liquid state at room temperature for ease of administration and accurate measurement of dose and would be converted into gel with increased residence time at the nasal physiological temperature range. 
Pintu Kumar De \& Souvik Ghatak; Saudi J Med Pharm Sci, Jan., 2020; 6(1): 91-101

In-vitro and Ex-vivo Drug Permeation Study

The results of In-Vitro and Ex-vivo

permeation study of drug from various formulations using dialysis membrane and goat nasal mucosa are depicted in Table-7.

Table-7: In-Vitro and Ex -Vivo drug Permeation \& Flux of In-Situ gel formulations

\begin{tabular}{|c|c|c|c|c|c|c|}
\hline \multirow[t]{2}{*}{$\begin{array}{l}\text { Formulation } \\
\text { code }\end{array}$} & \multicolumn{2}{|c|}{$\begin{array}{l}\text { Cumulative \% permeation } \\
\text { at } 6 \mathrm{hr}\end{array}$} & \multicolumn{2}{|c|}{ Permiability Co-efficient $(\mathrm{cm} / \mathrm{h})$} & \multicolumn{2}{|c|}{ Flux $\left(\mathrm{mg} / \mathrm{cm}^{2} / \mathrm{h}\right)$} \\
\hline & In-Vitro & Ex-Vivo & In-Vitro & Ex-Vivo & In-Vitro & Ex-Vivo \\
\hline F1 & $98.03 \pm 0.34$ & $96.49 \pm 1.49$ & $7.85 \times 10^{-2} \pm 0.007$ & $6.35 \times 10^{-2} \pm 0.001$ & $0.157 \pm 0.017$ & $0.127 \pm 0.007$ \\
\hline $\mathrm{F} 2$ & $96.08 \pm 0.37$ & $88.98 \pm 5.56$ & $7.6 \times 10^{-2} \pm 0.009$ & $5.85 \times 10^{-2} \pm 0.002$ & $0.152 \pm 0.012$ & $0.117 \pm 0.016$ \\
\hline F3 & $95.54 \pm 1.79$ & $81.82 \pm 0.76$ & $7.2 \times 10^{-2} \pm 0.005$ & $5.3 \times 10^{-2} \pm 0.004$ & $0.144 \pm 0.014$ & $0.106 \pm 0.013$ \\
\hline F4 & $87.38 \pm 1.86$ & $68.95 \pm 0.47$ & $5.25 \times 10^{-2} \pm 0.010$ & $4.5 \times 10^{-2} \pm 0.006$ & $0.105 \pm 0.021$ & $0.090 \pm 0.015$ \\
\hline F5 & $85.48 \pm 1.93$ & $58.77 \pm 0.36$ & $5.05 \times 10^{-2} \pm 0.004$ & $3.7 \times 10^{-2} \pm 0.005$ & $0.101 \pm 0.023$ & $0.074 \pm 0.016$ \\
\hline F6 & $77.33 \pm 1.57$ & $52.31 \pm 0.26$ & $4.75 \times 10^{-2} \pm 0.006$ & $3.3 \times 10^{-2} \pm 0.003$ & $0.095 \pm 0.020$ & $0.066 \pm 0.018$ \\
\hline
\end{tabular}

The Results depicted as Mean $\pm \mathrm{SD}(\mathrm{n}=3)$

From both the in - vitro \& Ex - vivo permeation study it is noted that the formulations containing lower \% of PF-127 (20\%) provide higher amount of drug release than the formulation containing higher \% of PF-127 (25\%). That may be due to lower viscosity \& less compact micellar structure of PF -127 in lower strength as it has been found by S. D. Desai [18].

The formulations with less $\%$ (F1, F2 and F3) of PF 127 gels shows higher permeability co - efficient and flux than the formulations with higher percentage (F4, F5, F6) of PF-127.

From the study of permeability co - efficient and flux values it is noted that as the concentration of PEG 6000 is increased in both the case the permeability co - efficient and flux were increased that may be due to permeation enhancing effect of PEG 6000 and its higher water solubility as well as its properties of formation of mixed micelle [19].

\section{Analysis of the Release Mechanism}

After performing the Ex - Vivo studies using goat nasal mucosa, the permeation profile of all the formulation is fitted to Zero Order model (cumulative $\%$ release vs. $\mathrm{t}$ in $\mathrm{h}$ ) in Fig-8, First Order model (log \% amount remaining to be released vs. $t$ in $h$ ) in Fig.9, Higuchi model cumulative amount release per $\mathrm{cm}^{2}$ vs. square root of time) in Fig-10 \& tabulated the regression co - efficient $\left(\mathrm{R}^{2}\right)$ \& release constant $(\mathrm{k})$ value in each case in Table-8. Again to study the mechanism of the permeation from them the data is fitted to Korsmeyer-Peppas model in Fig-11 \& the values of exponent ' $\mathrm{n}$ ' for each case has been tabulated in Table-9.

Table-8: Kinetic modeling of Ex-vivo permeation of drug through goat nasal mucosa

\begin{tabular}{|l|l|l|l|l|l|l|}
\hline \multirow{2}{*}{ Formulation } & \multicolumn{2}{|l|}{ First Order Model } & \multicolumn{2}{l|}{ Zero order Model } & \multicolumn{2}{l|}{ Higuchi Model } \\
\cline { 2 - 7 } & $\mathbf{R}^{2}$ value & K value & $\mathbf{R}^{2}$ value & K value & $\mathbf{R}^{2}$ value & K value \\
\hline F1 & 0.946 & 0.121 & 0.711 & 0.332 & 0.968 & 0.288 \\
\hline F2 & 0.934 & 0.089 & 0.901 & 0.304 & 0.938 & 0.262 \\
\hline F3 & 0.953 & 0.063 & 0.978 & 0.275 & 0.863 & 0.235 \\
\hline F4 & 0.981 & 0.044 & 0.987 & 0.235 & 0.848 & 0.199 \\
\hline F5 & 0.978 & 0.033 & 0.988 & 0.192 & 0.774 & 0.161 \\
\hline
\end{tabular}

Table-9: 'n' values of Korsmeyer-Peppas model

\begin{tabular}{|l|l|l|l|}
\hline Formulation code & nvalue & $\mathbf{R}^{2}$ value & Diffusion mechanism \\
\hline F1 & 0.646 & 0.998 & NON-FICIAN \\
\hline F2 & 0.868 & 0.991 & NON-FICIAN \\
\hline F3 & 1.039 & 0.992 & SUPER CASE II \\
\hline F4 & 1.002 & 0.994 & SUPER CASE II \\
\hline F5 & 1.075 & 0.993 & SUPER CASE II \\
\hline F6 & 1.171 & 0.995 & SUPER CASE II \\
\hline
\end{tabular}




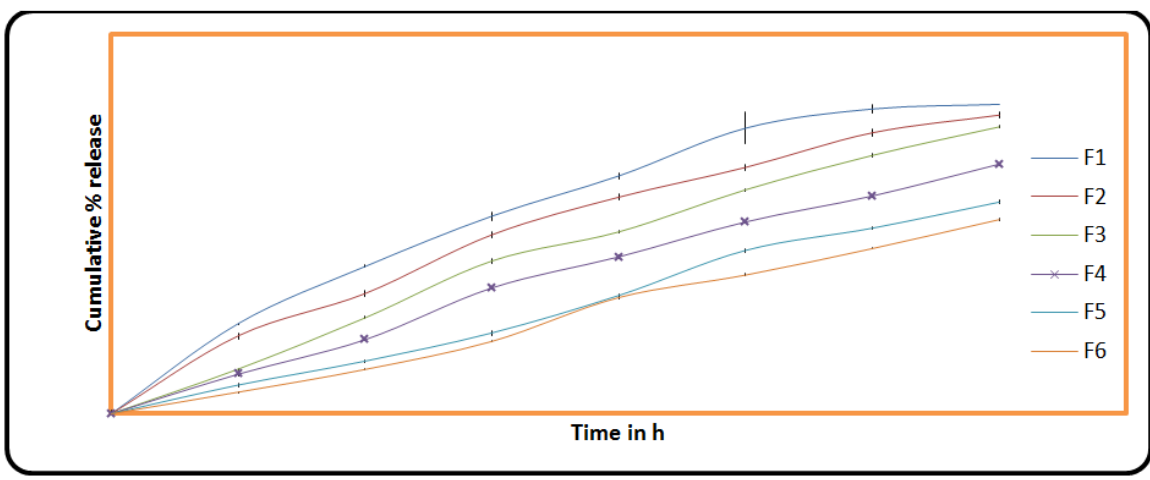

Fig-8: Zero Order Plot for Ex - Vivo Release of Ondansetron Hydrochloride through Goat Nasal Membrane

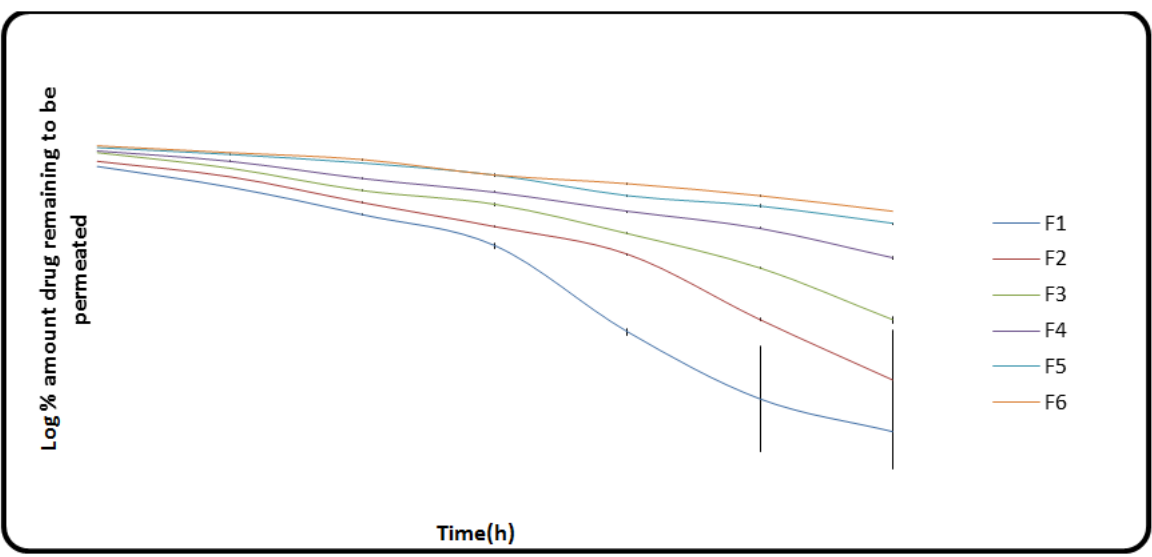

Fig-9: First Order Plot for Ex - Vivo Release of Ondansetron Hydrochloride through Goat Nasal Membrane

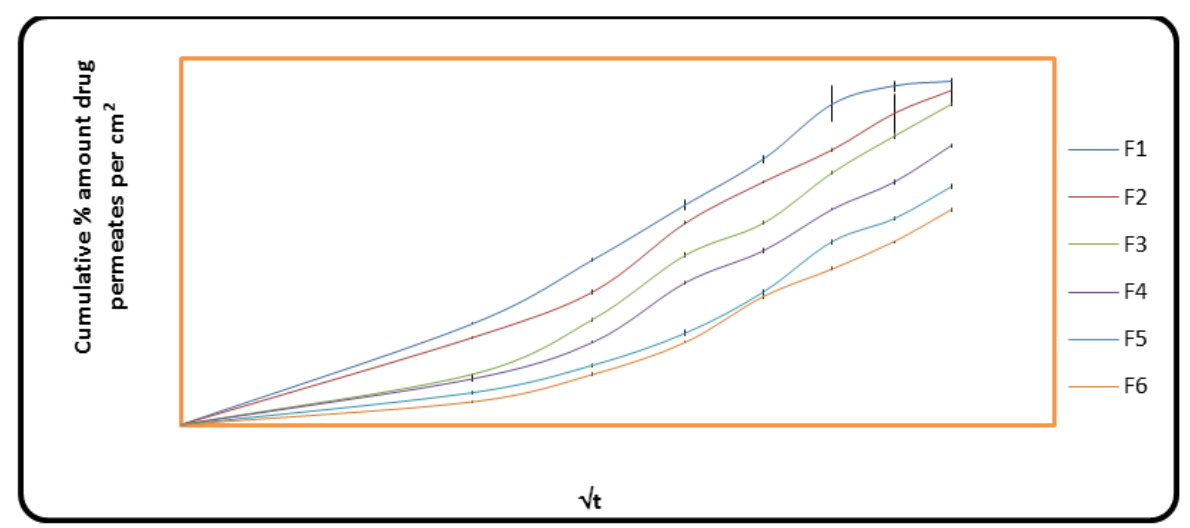

Fig-10: Higuchi Plot for Ex - Vivo Release of Ondansetron Hydrochloride through Goat Nasal Membrane

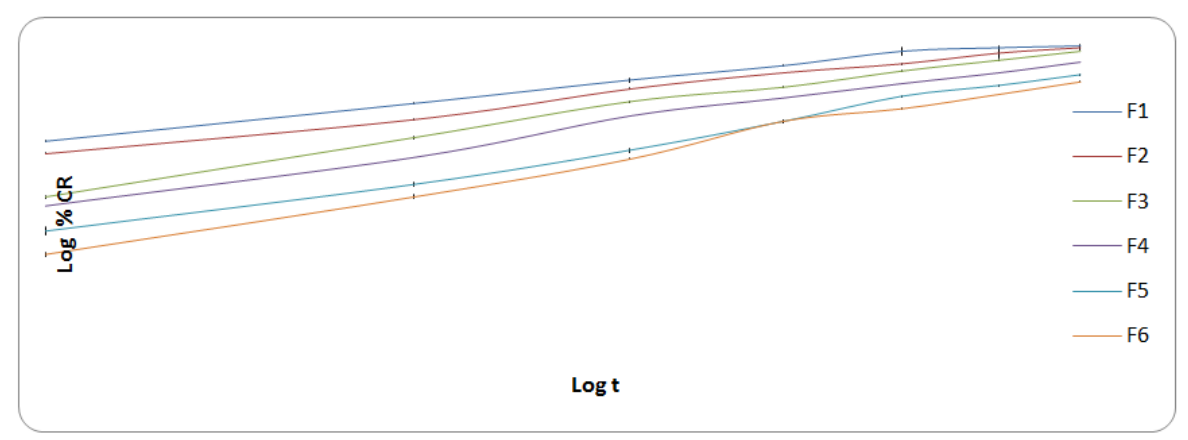

Fig-11: Korsmeyer-Peppas Plot for Ex - Vivo release of Ondansetron Hydrochloride through Goat Nasal Membrane

From the table of the regression value it is shown that the formulation F1\& F2 follow highest linearity to the Higuchi Model \& F3, F4, F5, F6 follow highest linearity to the first order model \& from the ' $n$ ' value of each formulation revealed that F1, F2 follow 
Non- Fickian release whereas F3, F4, F5, F6 follow the Super Case II release mechanism.

From the ex-vivo value of exponent ' $n$ ' of Korsmeyer-Peppas model we can conclude the permeation from $\mathrm{F} 1 \& \mathrm{~F} 2$ is diffusion \& erosion controlled, whereas the permeation from the F3, F4, F5 $\&$ F6 is due to the erosion of the polymeric chain.
From the results of the release mechanism it can be concluded that as the viscosity of the formulation is increased the release mechanism will transformed from Non - Fickian to Super Case II release mechanism.

\section{Stability Study}

The results of stability study as per ICH guideline for intermediate and accelerated conditions are depicted in Table-10.

Table-10: Stability study data after storing the formulations at Intermidiate and Accelerated Conditions for 6 month

\begin{tabular}{|l|l|l|l|l|l|l|l|l|l|l|l|l|}
\hline Condition & \multicolumn{4}{|l|}{ Intermediate condition for 6 months } & \multicolumn{4}{|l|}{ Accelerated condition for 6 months } \\
\hline Formulation code & F1 & F2 & F3 & F4 & F5 & F6 & F1 & F2 & F3 & F4 & F5 & \\
\hline Drug content (\%) & 98.7 & 97.3 & 98.8 & 99.2 & 97.8 & 97.2 & 98.48 & 97.06 & 97.95 & 98.6 & 98.23 & 97.00 \\
\hline pH & 5.45 & 5.51 & 5.87 & 5.12 & 5.19 & 5.16 & 5.69 & 5.89 & 5.32 & 5.37 & 5.19 & 5.66 \\
\hline $\begin{array}{l}\text { Gelation Temperature } \\
\left({ }^{\circ} \mathrm{C}\right)\end{array}$ & 31.26 & 32.18 & 32.97 & 25.73 & 26.65 & 28.67 & 31.45 & 32.75 & 33.23 & 25 & 26.28 & 28.89 \\
\hline Clarity & & & & & & & & & & & & \\
\hline
\end{tabular}

There are no major changes found out in the formations after storing at intermediate and accelerated conditions as per ICH guidelines Q1A in terms of content uniformity, $\mathrm{pH}$, gelation temperature and clarity. The results were corroborating with the findings of Mandal et al., [20].

\section{Conclusion}

A clear In-Situ gel can be formulated using thermosensitive polymer PF 127 in combination of mucoadhesive polymers HPMC E15 and PEG 6000, which releases the drug, Ondansetron $\mathrm{Hcl}$ for sustaining the action through nasal route. The FTIR study confirms the compatibility of the ondansetron with other formulation components. Optimum Concentration of PF-127 was found $20-25 \%$ to get gelation temperature of formulations in the nasal physiological temperature range. From the results of the release mechanism it can be concluded that as the viscosity of the formulation is increased, the release mechanism will be transformed from Non - Fickian to Super Case II.

\section{REFERENCES}

1. Dressman, J. B., Thelen, K., \& Jantratid, E. (2008). Towards quantitative prediction of oral drug absorption. Clinical pharmacokinetics, 47(10), 655-667.

2. Shinichiro, H., Takatsuka, Y., Tai, M., \& Hiroyuki, M. (1981). Absorption of drugs from the nasal mucosa of rat. International Journal of Pharmaceutics, 7(4), 317-325.

3. Illum, L. (2003). Nasal drug deliverypossibilities, problems and solutions. Journal of controlled release, 87(1-3), 187-198.

4. Dahl, A. R., \& Lewis, J. L. (1993). Respiratory tract uptake of inhalants and metabolism of xenobiotics. Annual review of pharmacology and toxicology, 33(1), 383-407.

5. Talegaonkar, S., \& Mishra, P. R. (2004). Intranasal delivery: An approach to bypass the blood brain barrier. Indian journal of pharmacology, 36(3), 140-147.

6. Davis, S. S. (2001). Nasal vaccines. Adv Drug Deliv Rev, 51, 21-42.

7. Cheng, Y. H., Watts, P., Hinchcliffe, M., Hotchkiss, R., Nankervis, R., Faraj, N. F., ... \& Illum, L. (2002). Development of a novel nasal nicotine formulation comprising an optimal pulsatile and sustained plasma nicotine profile for smoking cessation. Journal of controlled release, 79(1-3), 243-254.

8. Tas, C., Ozkan, C. K., Savaser, A., Ozkan, Y., Tasdemir, U., \& Altunay, H. (2006). Nasal absorption of metoclopramide from different Carbopol ${ }^{\circledR} 981$ based formulations: In vitro, ex vivo and in vivo evaluation. European journal of pharmaceutics and biopharmaceutics, 64(2), 246254.

9. Schmolka, I. R. (1972). Artificial skin I. Preparation and properties of pluronic F- 127 gels for treatment of burns. Journal of biomedical materials research, 6(6), 571-582.

10. Choi, H. G., Jung, J. H., Ryu, J. M., Yoon, S. J., Oh, Y. K., \& Kim, C. K. (1998). Development of in situ-gelling and mucoadhesive acetaminophen liquid suppository. International journal of pharmaceutics, 165(1), 33-44.

11. Choi, H. G., Oh, Y. K., \& Kim, C. K. (1998). In situ gelling and mucoadhesive liquid suppository containing acetaminophen: enhanced bioavailability. International journal of pharmaceutics, 165(1), 23-32.

12. Korsmeyer, R. W., Gurny, R., Doelker, E., Buri, P., \& Peppas, N. A. (1983). Mechanisms of solute 
release from porous hydrophilic polymers. International journal of pharmaceutics, 15(1), 25-35.

13. Nandgude, T., Thube, R., Jaiswal, N., Deshmukh, P., Chatap, V., \& Hire, N. (2008). Formulation and evaluation of $\mathrm{pH}$ induced In-Situ nasal gel of salbutamol sulphate. Int $J$ Pharm Sci Nanotechnol, 1, 177-82.

14. Pisal, S., Shelke, V., Mahadik, K., \& Kadam, S. (2004). Effect of organogel components on in vitro nasal delivery of propranolol hydrochloride. Aaps Pharmscitech, 5(4), 92-100.

15. Dash, S., Murthy, P. N., Nath, L., \& Chowdhury, P. (2010). Kinetic modeling on drug release from controlled drug delivery systems. Acta Pol Pharm, 67(3), 217-23.

16. Levy, M. H., Rosen, S. M., \& Kedziera, P. (1992). Transdermal fentanyl: seeding trial in patients with chronic cancer pain. Journal of pain and symptom management, 7(3), S48-S50.
17. Salem, II., Tose, M., Lopez, R., \& Galan, A. C. Analytical Profiles of drug substances and excipients, 27, 319.

18. Desai, S. D., \& Blanchard, J. (1998). In vitro evaluation of pluronic F127-based controlledrelease ocular delivery systems for pilocarpine. Journal of pharmaceutical sciences, 87(2), 226-230.

19. Shah, S. N. H., Tahir, M. A., Safdar, A., Riaz, R., Shahzad, Y., Rabbani, M., ... \& Murtaza, G. (2013). Effect of permeation enhancers on the release behavior and permeation kinetics of novel tramadol lotions. Tropical Journal of Pharmaceutical Research, 12(1), 27-32.

20. Mandal, S., Thimmasetty, M. K., Prabhushankar, G. L., \& Geetha, M. S. (2012). Formulation and evaluation of an in situ gel-forming ophthalmic formulation of moxifloxacin hydrochloride. International journal of pharmaceutical investigation, 2(2), 78-82. 